\section{Buchrezension zu: Bioanalytik für Einsteiger}

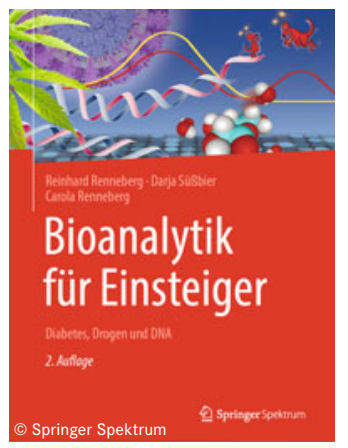

Bioanalytik für Einsteiger Diabetes, Drogen und DNA Reinhard Renneberg, Darja Süßbier und Carola Renneberg

272 S., viele Abb. und Tab., Springer Spektrum, 2. Aufl., 2021. SC, 37,99 €. ISBN: 9783662616338

DOI: $10.1007 / \mathrm{s} 12268-022-1693-\mathrm{x}$ (C) Die Autorin 2022

Das Feld der Bioanalytik hat in der letzten Zeit, natürlich auch bedingt durch die Coronakrise, eine erhebliche Zahl an Interessierten gewonnen. Das hier vorgelegte Lehrbuch ist für Einsteiger:innen gedacht und bietet einen wunderbaren Überblick über das Feld der Bioanalytik, bei dem auch Virus- und Drogentests und viele weitere topaktuelle Themen anschaulich beschrieben werden. Auch das Geschichtliche kommt nie zu kurz.

Es ist kein Buch für Menschen, die tief in das Fachgebiet einsteigen wollen, trotzdem halte ich es für Studierende und auch Lehrende der Bioanalytik oder verwandten Gebieten geeignet - für alle, die einen Überblick brauchen und dabei nicht abgeschreckt, sondern für Bioanalytik und Wissenschaft interessiert werden wollen und sollen.

Das Buch ist hervorragend geschrieben und der Lernstoff ist alles andere als langweilig und trocken. Tolle Illustrationen von Darja Süßbier, Cartoons, Fotos und Expertenmeinungen machen das Ganze anschaulich und abwechslungsreich. Besonders gefiel mir das Vorwort, das nicht, wie oft üblich, aus seitenlangem Text besteht, sondern kurz ausfällt und von vielen Fotos illustriert wird. Auf den folgenden Seiten erzählt der Autor, wie er zum Bioanalytiker wurde, wobei er sehr nahbar und sympathisch erscheint.

Nach der ebenso lehrreichen wie auch putzigen Geschichte des Nanuru, die ein:e Anfänger:in auf dem Fachgebiet der Bioanalytik wohl erst nach der Lektüre des restlichen Buchs so richtig versteht, folgen Kapitel zur Untersuchung von Biomolekülen, Biokatalyse, Bioaffinität I und II, DNA, RNA und ihre Amplifikation sowie Biosensoren. Jedes Kapitel endet mit Tipps für Literatur, Weblinks und Fragen zur Selbstkontrolle. „Boxen“ und verschiedene Exkurse vermitteln Historie und analytische oder technische Details.

Das Modell der Glucose-Oxidase zum Selberbauen hat mir gut gefallen. Obwohl man sein Buch zum Aufbau nicht Zerschneiden muss, habe ich mich gefragt, wie viele Leser dieses Modell wohl tatsächlich schon gebastelt haben. Zugegeben, ich war noch nie eine Bastlerin und gehöre nicht dazu. Die Idee hat mir trotzdem gefallen.

Gut gelungen ist auch der Abschluss, bei dem die Geschichte der Bioanalytik anhand verschiedener Briefmarken aus vielen Ländern der Erde illustriert wird.

Ich war schon Fan der ersten Auflage - von der zweiten bin ich ebenfalls begeistert!

Sie wurde, so steht es geschrieben, buchstäblich bis zur letzten Minute überarbeitet und auf den neusten Stand gebracht. Am Ende folgt ein Corona-Epilog, der das Buch brandaktuell macht, der aber trotzdem aufgrund der rasenden Wissensentwicklung auf dem Gebiet schon wieder überholt ist. Das kann man sicher verzeihen!
Susanne Aileen Funke,

Hochschule für angewandte Wissenschaften Coburg, aileen.funke@hs-coburg.de

Diese Rezension erscheint Open Access. *

* Funding note: Open Access funding enabled and organized by Projekt DEAL. Open Access: Dieser Artikel wird unter der Creative Commons Namensnennung 4.0 International Lizenz veröffentlicht, welche die Nutzung, Vervielfältigung, Bearbeitung, Verbreitung und Wiedergabe in jeglichem Medium und Format erlaubt, sofern Sie den/die ursprünglichen Autor(en) und die Quelle ordnungsgemäß nennen, einen Link zur Creative Commons Lizenz beifügen und angeben, ob Änderungen vorgenommen wurden. Die in diesem Artikel enthaltenen Bilder und sonstiges Drittmaterial unterliegen ebenfalls der genannten Creative Commons Lizenz, sofern sich aus der Abbildungslegende nichts anderes ergibt. Sofern das betreffende Material nicht unter der genannten Creative Commons Lizenz steht und die betref. fende Handlung nicht nach gesetzlichen Vorschriften erlaubt ist, ist für die oben aufgeführten Weiterverwendungen des Materials die Einwilligung des jeweiligen Rechteinhabers einzuholen. Weitere De tails zur Lizenz entnehmen Sie bitte der Lizenzinformation auf

http://creativecommons.org/licenses/ by $/ 4.0 /$ deed.de. 